\title{
EFEK PIN HOLE UNTUK MENEKAN EFEK MULTILENSA PADA KOMUNIKASI FREE SPACE OPTICS
}

\section{PIN HOLE EFFECT FOR SUPPRESSING MULTILENS IN FREE SPACE OPTICAL COMMUNICATION}

\author{
Tri Nopiani Damayanti,ST.,MT ${ }^{1}$; Purnomo Sidi Priambodo,Ir.,M.SC.,Ph.D ${ }^{2}$ \\ ${ }^{1}$ Prodi D3 Teknik Telekomunikasi, Fakultas Ilmu Terapan Universitas Telkom \\ ${ }^{2}$ Departemen Teknik Elektro Fakultas Teknik Universitas Indonesia \\ 12damayanti@tass.telkomuniversity.ac.id; ${ }^{2}$ pspriambodo@ee.ui.ac.id
}

\begin{abstract}
Abstrak
Teknologi FSOC pada jaringan teresterial memanfaatkan media atmosfer yang sangat terpengaruh kondisi cuaca sebagai media propagasi informasi sinyal optik. Pengaruh kondisi cuaca ini menyebabkan media atmosfer mengalami turbulens. Akibat turbulens atmosfer, teknologi FSOC dihadapkan oleh tantangan terbesar dimana salah satunya terjadi efek multi lensa akibat gradient temperature di atmosfer yang menyebabkan sinar meleset dari titik penerima.

Gangguan yang terjadi pada FSOC bersifat random dan fluktuatif dalam domain spasial dan waktu sehingga dilakukan pendekatan secara statistik untuk menganalisa gelombang yang dipropagasikan pada sistem FSOC. Pengujian eksperimen penelitian melalui pendekatan dengan teknik SISO FSOC (Single-input single output) dengan menggunakan laser He-Ne pada panjang gelombang $632 \mathrm{~nm}$. Sistem dirancang dengan menggunakan pin hole di receiver FSOC dimana pada eksperimen ini terjadi peningkatan nilai SNR sebesar $7.3443 \mathrm{~dB}$ saat sistem diuji menggunakan pin hole $10 \mu \mathrm{m}$.
\end{abstract}

Kata kunci : FSOC,SISO, turbulens, pin hole, SNR

\begin{abstract}
FSOC technology on terrestrial networks utilizing atmospheric media are greatly affected the weather conditions as the optical signal information propagation medium. The influences of weather conditions have caused turbulences in atmospheric. Due to atmospheric turbulence, technology FSOC biggest challenges faced by which one multi-lens effect occur due to the temperature gradient in the atmosphere which causes the beam misses the receiving point.

Disruption of the FSOC random and fluctuating in the spatial domain and time so do statistical approach to analyze the wave that propagated the FSOC system. We used approach FSOC SISO (single-input single output) using He-Ne laser at a wavelength of $632 \mathrm{~nm}$. The system is designed by using a pin hole in the receiver FSOC which in this experiment SNR increase of $7.3443 \mathrm{~dB}$ when the system was tested using a pin hole $10 \mu \mathrm{m}$.
\end{abstract}

Keywords : FSOC,SISO, turbulens, pin hole, SNR

\section{PENDAHULUAN}

Kebutuhan akan kecepatan akses informasi layanan data serta aksesibilitas pengguna informasi saat ini menjadi prioritas utama dalam dunia industri telekomunikasi. Pemenuhan kecepatan data ini dilakukan dengan berbagai inovasi teknologi yang sudah diterapkan seperti wireless, 
broadband, 3G, CDMA bahkan 4G yang mengikuti pola kebutuhan user yang selalu bergerak tanpa batas [1]. Kebutuhan informasi yang besar dengan kualitas layanan informasi yang handal mengakibatkan dibutuhkannya bandwidth transmisi sinyal informasi yang besar pada infrastruktur jaringan telekomunikasi.

Teknologi telekomunikasi yang dapat mendukung kebutuhan jaringan akan bandwidth yang besar, reliabilitas serta mobilitas dengan kualitas layanan yang handal adalah teknologi Free Space Optical Communication System (FSOC) [2]. Teknologi Free Space Optical Communication System (FSOC) dapat mengatasi masalah "access network bottleneck" terutama pada jaringan teresterial dengan memanfaatkan media atmosfir tanpa pemandu gelombang [3]. Teknologi FSOC mulai banyak diminati karena memiliki keuntungan yaitu spektrum frekuensinya yang tidak berlisensi dan memiliki kapasitas bandwidth yang besar dibandingkan dengan teknologi telekomunikasi yang berbasis kabel tembaga (LAN) dan radio (wireless, 3G, CDMA dan 4G) [4].

Penggunaan media atmosfir sebagai media propagasi/perambatan berkas cahaya pada FSOC merupakan tantangan terbesar dalam penerapan teknologi FSOC sebagai sistem komunikasi. Atmosfir bukan merupakan media yang ideal karena kondisi atmosfir dipenuhi berbagai jenis partikel yang tidak seragam baik dari jenisnya dan ukurannya yang dapat mengakibatkan terjadinya gradient temperature di atmosfer. Gradient temperature dapat mengakibatkan efek multi lensa (sintilasi) disepanjang garis lurus transmisi sehingga sinar meleset dari titik penerima mengakibatkan akan terjadinya pelemahan intensitas cahaya yang merambat menyebabkan degradasi SNR dan BER [5].

Untuk meningkatkan kinerja receiver dan meminimalisasi noise yang diakibatkan oleh efek turbulensi berbagai teknik telah dikembangkan untuk mengatasi permasalahan tersebut. Penelitian yang telah dikembangkan sejauh ini adalah penerapan APD MIMO pada Receiver oleh Neda.C [4]. Penelitian ini menggunakan teknik Gaussian Model dengan metode Maximum Like Hood dan Equal Gain Combining (EGC) dengan menghasilkan peningkatan kinerja $12 \mathrm{~dB}$ untuk 4 APD dibandingkan menggunakan 1 APD dengan noise thermal yang rendah. Penerapan teknik filtering dengan metode spatial diversity pada receiver dengan proses random distribusi $\mathrm{K}$ pada SIMO (Single Input Multiple Output) sistem FSO telah diusulkan oleh Theodoros A dengan hasil terjadi peningkatan BER sebesar $10^{-9}$ dengan nilai SNR lebih dari 5[6]. Bikram Beri juga berhasil melakukan investigasi performansi WDM pada system FSOC yang menggunakan APD Photodiode dengan filter Bessel dengan keberhasilan peningkatan BER dalam orde $10^{-12}$ [7].

Penelitian ini menggunakan tube propagation simulator dimana pada receiver ditempatkan pin hole sebagai lensa fourier optics spasial spectral analyzer dengan diameter yang proporsional dan komparabel dengan panjang gelombang cahaya yang digunakan sebesar $632 \mathrm{~nm}$. Penggunaan pin hole pada receiver bertujuan untuk memfilter noise propagasi yang telah menjadi noise spasial frekuensi tinggi setelah melewati proses pemfokusan cahaya oleh lensa yang akan menghilangkan efek multilensa sehingga akan meningkatkan nilai SNR.

\section{DASAR TEORI}

Pada sistem Free Space Optics Communication (FSOC), besarnya daya yang diterima $\left(P_{R x}\right)$ tergantung pada daya yang dikirim $\left(P_{T x}\right)$ yang dipengaruhi oleh kondisi atmosfer sebagai media propagasinya. Media propagasi yang digunakan pada sistem FSOC bukan merupakan media yang ideal karena sangat dipengaruhi beberapa hal yang akan menyebabkan terjadinya noise (derau) pada sinyal informasi yang dikirimkan, yaitu [5] : (1) absorpsi dan hamburan sinar oleh partikel gas yang mengakibatkan peredaman atau attenuasi sinyal informasi yang ditransmisikan; (2) gradient temperature di atmosfer yang mengakibatkan efek multi lensa (sintilasi) disepanjang 
garis lurus transmisi yang menyebabkan sinar meleset dari titik penerima; (3) turbulensi udara yang menyebabkan distribusi tekanan udara sebagai fungsi waktu, sehingga terjadi perubahan arah sinar dan derau pada front wave sebagai fungsi waktu. Ketiga permasalahan tersebut dapat menyebabkan degradasi Signal to Noise Ratio (SNR) dan Bit Error Rate (BER) pada sisi Penerima (RX). Sistem FSOC teresterial dapat dibagi menjadi tiga bagian yaitu : Transmitter(TX), Atmospheric Channel dan Receiver $(R X)$. Berikut ini gambar blok diagram Sistem FSOC Teresterial [8] :

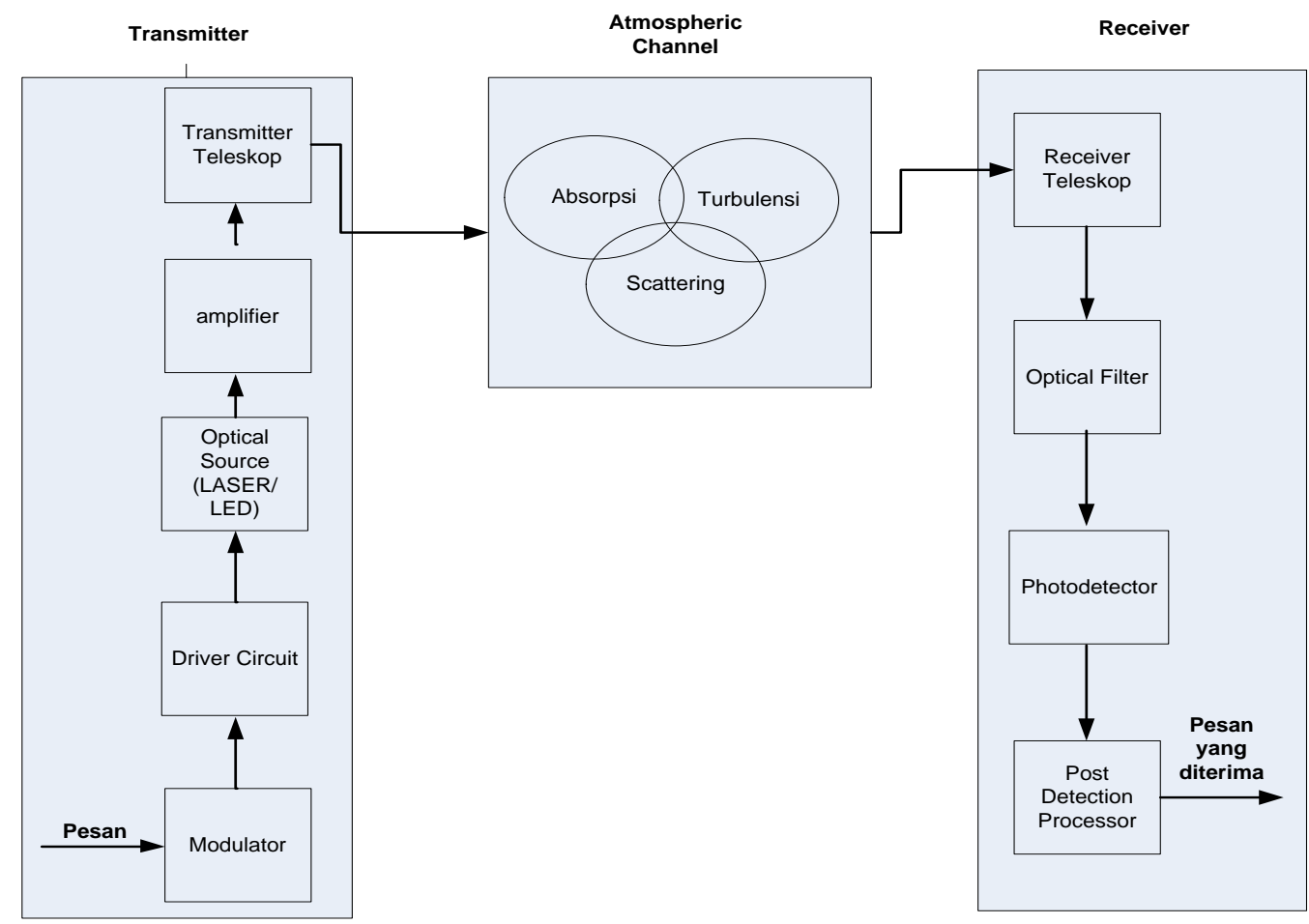

Gambar 1. Sistem FSOC

Blok Tx memiliki fungsi utama untuk memodulasi sumber data ke optical carrier yang dipropagasikan melalui saluran atmosfer (atmospheric channel). Pada TX, teleskop berfungsi mengumpulkan, mengkolimasikan dan mengarahkan radiasi optik ke teleskop Rx. Pada Rx, teleskop berfungsi untuk mengumpulkan dan memfokuskan radiasi optik yang datang ke photodetektor.

Pada saluran atmosphere, ketika gelombang yang dipropagasikan di pengaruhi oleh efek turbulensi yang menyebabkan distribusi tekanan udara sebagai fungsi waktu sehingga akan terjadi perubahan arah sinar dan derau (noise) pada front wave sebagai fungsi waktu yang akan menyebabkan kualitas SNR di komunikasi analog dan BER di komunikasi digital menurun. Untuk intesitas modulasi sistem daya optik yang diterima pada receiver $P_{r}(t)$ yang dipengaruhi oleh turbulensi atmosfer dapat dihitung dalam persamaan sebagai berikut [9] :

$$
P_{r}(t)=P_{S}(t) T(t)+n(t)
$$

$P_{S}(t)$ adalah Intensitas optik yang diterima tanpa adanya turbulensi, $n(t)$ adalah Adaptive White Gaussian Noise (AWGN) dan $T(t)$ adalah stationary random process akbat pengaruh turbulens. 
Pada saat udara cerah (clear atmosphere) tantangan utama yang dihadapi sistem FSOC adalah efek fluktuasi turbulens pada kinerja sistem terutama untuk link yang melebihi $1 \mathrm{~km}$. Turbulensi Atmosfir disebabkan oleh fluktuasi acak spasial dan temporal dari indeks bias (refractive index) karena temperatur, tekanan, dan variasi angin di sepanjang jalur propagasi optik tersebut sebagai fungsi waktu sehingga terjadi perubahan arah sinar dan derau pada front wave sebagai fungsi waktu. Efek dari turbulensi atmosfir akan mempengaruhi nilai Signal to Noise Ratio (SNR) dan Bit Error Rate (BER) kinerja sistem FSOC. Pengaruh efek turbulensi atmosfir yang tergantung pada kondisi cuaca mengakibatkan noise sinyal yang bervariasi secara spasial dan temporal sehingga akan menimbulkan efek multi lensa atau beam wandering disepanjang garis lurus transmisi. Pengaruh partikel debu di media mengakibatkan adanya cross section noise dua dimensi (2-D) pada receiver.

Propagasi gelombang optik pada sistem FSOC teresterial yang dilakukan pada penelitian ini dapat dianalisis sebagai superposisi gelombang menggunakan prinsip fourier optik. Analisis ini didasarkan atas fungsi dari waktu $\mathrm{f}(\mathrm{t})$ sebagai fungsi dari superposisi dari frekuensi yang berbeda. Hal ini dapat dilihat pada gambar 2.2 dibawah ini :

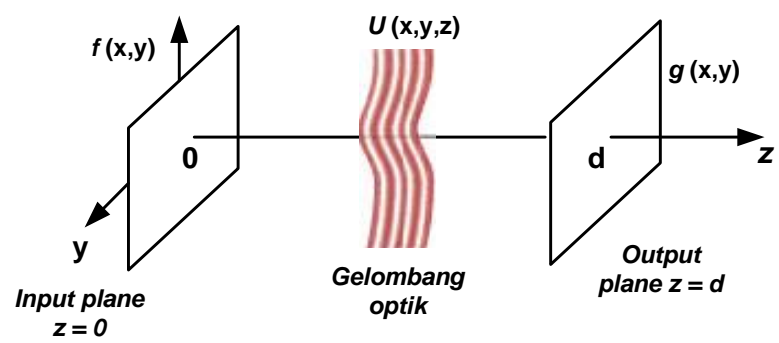

Gambar 2. Propagasi gelombang optik pada sistem FSOC

Variable $\mathrm{x}$ dan y merepresentasikan spasial koordinat dari plane sebagai superposisi dari fungsi harmonic $\mathrm{x}$ dan y yang dapat dituliskan sebagai berikut :

$$
f(x, y)=F\left(V_{x}, V_{y}\right) \exp \left[-j 2 \pi\left(V_{x} x+V_{y} y\right]\right.
$$

Dimana $F\left(V_{x}, V_{y}\right)$ adalah Amplitudo kompleks dan $V_{x}$ dan $V_{y}$ adalah spatial frequency. Pada spatial filtering yang menggunakan fourier optik hal yang terpenting pada gelombang optik adalah plane wave yang ditunjukkan oleh persamaan fungsi harmonik berikut:

$$
U(x, y, z)=A \exp \left[-j\left(k_{x} x+k_{y} y+k_{z} z\right)\right]
$$

Dimana $\left(k_{x}, k_{y}, k_{z}\right)$ adalah koefisien dari faktor gelombang $\mathrm{k}$ dan A adalah amplitude kompleks konstan.

Transformasi fourier dari superposisi dua gelombang dari persamaan 2.2 didapatkan sebagai berikut :

$$
F\left(v_{x}, v_{y}\right)=\int_{-\infty}^{\infty} f(x, y) \exp \left[j 2 \pi\left(v_{x} x+v_{y} y\right] d x d y\right.
$$

Sehingga persamaan superposisi gelombang yang ditransmisikan $U(x, y, z)$ didefinisikan sebagai berikut : 
$U(x, y, z)=\iint_{-\infty}^{\infty} F\left(v_{x}, v_{y}\right) \exp \left[-j\left(2 \pi v_{x} x+2 \pi v_{y} y\right)\right] \exp \left(-j k_{z} z\right) d v_{x} d v_{y}$

Saat tidak ada turbulens pada atmosfir di media propagasi maka besarnya nilai SNR didefinisikan sebagai berikut :

$$
S N R_{0}=\sqrt{\frac{\eta P_{s}}{2 h v B}}
$$

Dimana $\eta$ adalah efisiensi kuantum dari photodetektor, Ps adalah intensitas sinyal penerima, $\mathrm{v}$ adalah frekuensi cahaya, $\mathrm{h}$ adalah konstanta planck dan B adalah Bandwidth.

Saat terjadi turbulens pada atmosfir dimedia propagasi maka besarnya nilai SNR dapat didefinisikan sebagai berikut :

$$
\langle S N R\rangle=\frac{S N R_{0}}{\sqrt{1+\sigma_{I}^{2} D_{G} S N R_{0}^{2}}}
$$

Dimana $\sigma_{I}^{2}\left(0, L+L_{f}\right)=\sigma_{I}^{2}\left(D_{G}\right)$ adalah flux variance dan tergantung pada diameter bidang penerimaan lensa.

\section{METODE EKSPERIMEN}

Penelitian yang dilakukan eksperimen menggunakan Laser $\mathrm{He}$ - $\mathrm{Ne}$ dengan panjang gelombang $632 \mathrm{~nm}$ dan daya ouputnya sebesar 20. Laser ini merupakan salah satu tipe laser dimana medium aktif dari laser tersebut adalah gas helium neon. Berikut adalah gambar 3 blok diagram set-up eksperimen penelitian yang dilakukan:

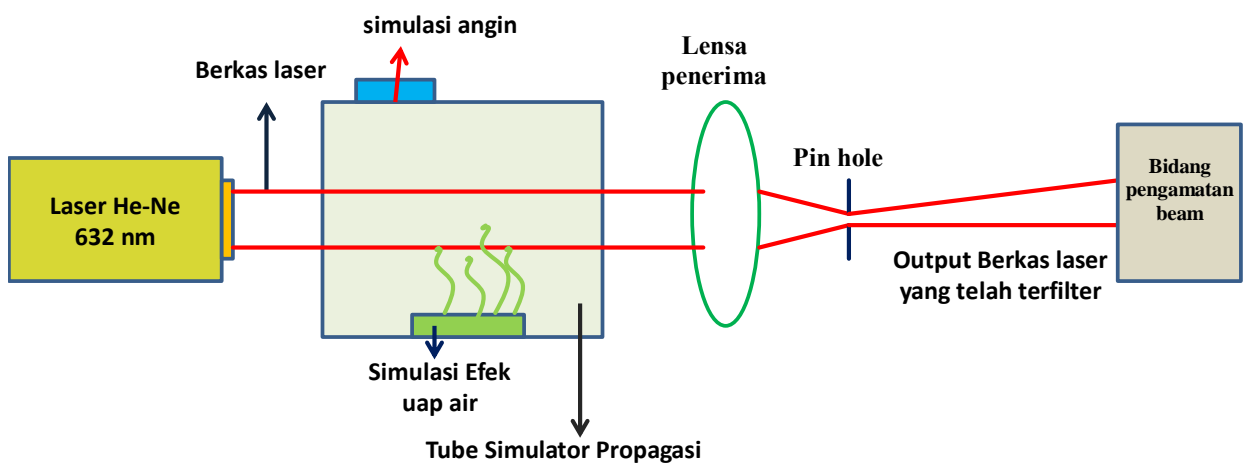

Gambar 3. Pemodelan Eksperimen FSOC

Pengukuran Beam RX dilakukan melalui dua skenario pengujian sistem yaitu tanpa adanya gangguan turbulens dan dengan adanya gangguan turbulens yang disebabkan oleh angin dan uap air. Gambar 4 merupakan gambar dari hasil pengujian eksperimen, terlihat bahwa saat pengujian eksperimen tanpa turbulens gambar yang dihasilkan pada (a) terpengaruh noise yang hanya disebabkan oleh spasial noise (b) beam yang dihasilkan telah terpengaruh noise spasial dan temporal noise dimana temporal noise disebabkan oleh efek turbulens berupa uap air dan angin. Pada gambar (b) terlihat bahwa noise spasial dan temporal lebih tersebar disekitar beam. 


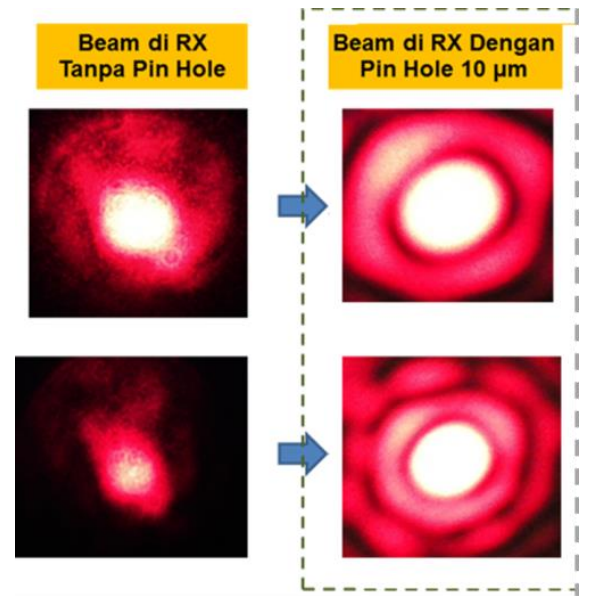

Gambar 4. Berkas Beam di receiver

Pada gambar 5 merupakan intensitas input cross section sepanjang sumbu x maka akan menghasilkan intensitas Gaussian beam yang ditumpangi oleh noise. Pada (a) input Gaussian beam yang ditumpangi oleh noise terlihat bahwa noise yang dihasilkan akibat gangguan kotoran debu dilensa lebih sedikit dibandingkan pada (b) yang telah mengalami noise temporal akibat gangguan turbulens dan akibat noise spasial oleh kotoran debu di lensa. Semakin kecil pin hole yang digunakan maka semakin banyak noise yang dapat difilter sehingga beam outputnya akan semakin bersih dari noise.
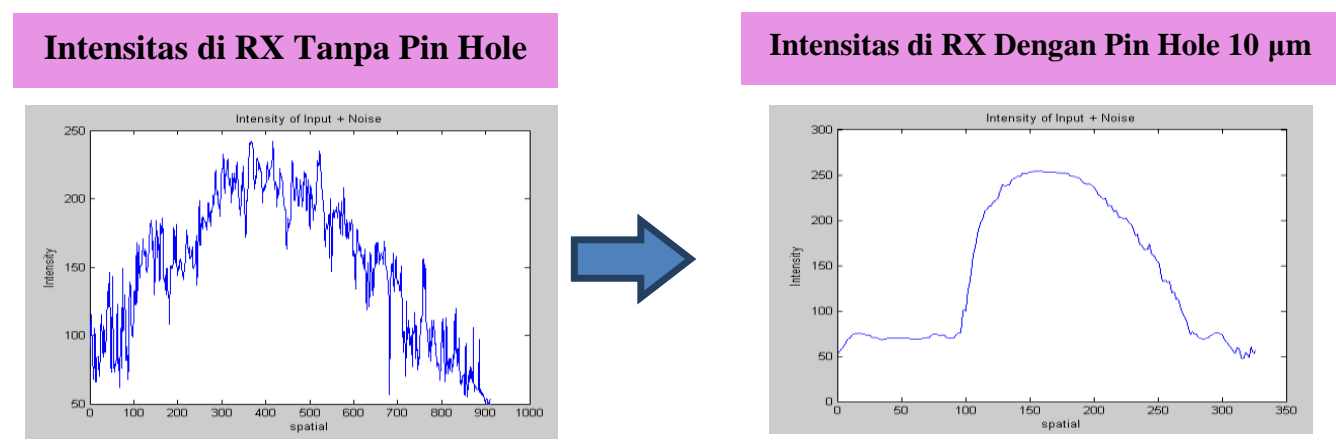

(a) Tanpa Turbulens
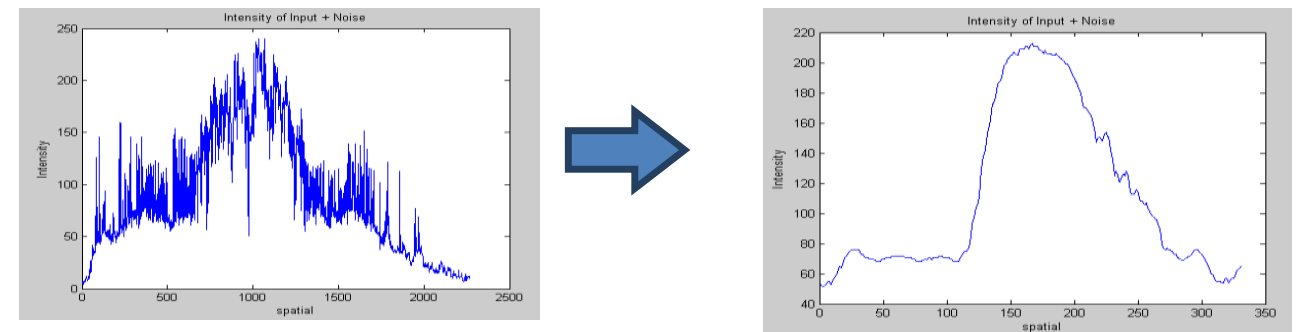

(b) Dengan Turbulens

Gambar 5. Intensitas input yang ditumpangi Noise di Receiver

Pada gambar 6 saat intensitas dinormalisasi sepanjang sumbu $\mathrm{x}$ dengan menggunakan fourier Transform 1-D akan didapatkan mode fundamental yang memiliki energi sinyal yang besar yang ditunjukkan pada sumbu x pada titik 0 , untuk energi sinyal rendah yang berada disekitar mode fundamental menggambarkan noise (dalam bentuk low frequence harmonic). Pada pengujian 
eksperimen dihasilkan nilai Signal Noise Ratio (SNR) pada 2-D saat tanpa gangguan pada gambar 6 dengan menggunakan pin hole $10 \mu \mathrm{m}$ SNR sebesar $14.6979 \mathrm{~dB}$.

Pada saat pengujian eksperimen menggunakan efek turbulens, terjadi kenaikan nilai SNR akibat pengaruh dari diameter pin hole sebagai filter spasial optik dimana pada saat menggunakan pin hole $10 \mu \mathrm{m}$ sebesar $13.4854 \mathrm{~dB}$.

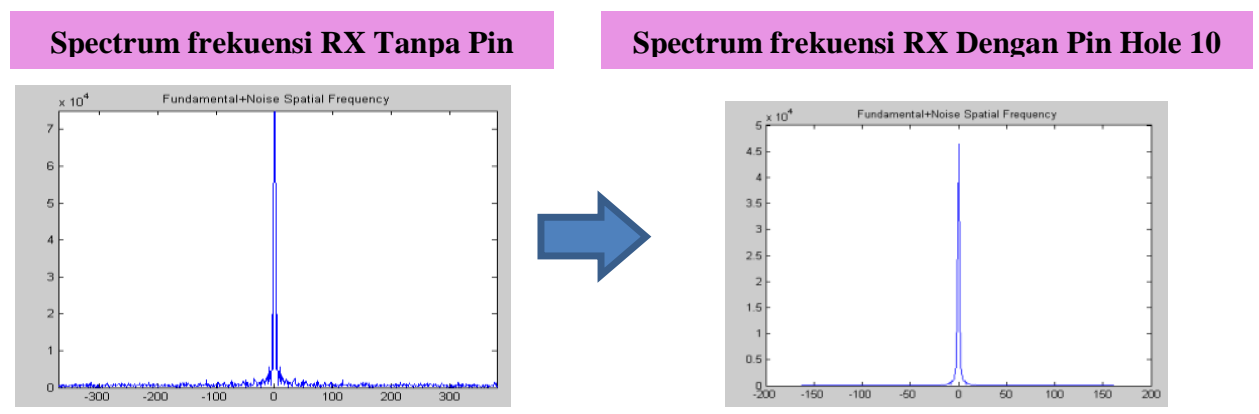

(a) Tanpa Turbulens
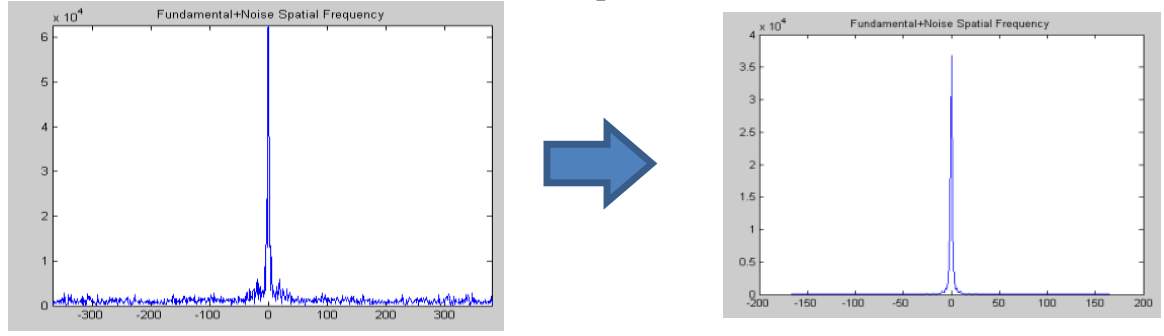

(b) Dengan Turbulens

Gambar 6. Spektrum Frekuensi Beam di Rx

\section{KESIMPULAN}

Berdasarkan hasil simulasi dan eksperimen yang dilakukan dapat disimpulkan sebagai berikut :

1. Teknik Fourier optics spatial spectral analyzer yang melakukan pemisahan high frekuensi spasial yang ditumpangi temporal noise menjadi terdistribusi berdasarkan sudut diffraksi oleh lensa receiver dan menggunakan pin hole sebagai low pass filter telah memberikan nilai SNR cross section 1-D pada kondisi tanpa turbulens, menggunakan pin hole $10 \mu \mathrm{m}$ dibandingkan tanpa pin hole mengalami peningkatan SNR sebesar 7.3443 dB.

2. Pada pengujian menggunakan efek turbulens yang dipengaruhi oleh noise spasial dan temporal noise, nilai SNR cross section 1-D tanpa pin hole hasil yang didapatkan nilainya jauh lebih kecil dibandingkan saat menggunakan filter spasial pin hole. Nilai SNR saat menggunakan pin hole $10 \mu \mathrm{m}$ dibandingkan tanpa pin hole mengalami peningkatan SNR sebesar $9.3268 \mathrm{~dB}$

\section{DAFTAR PUSTAKA}

[1] John B. Groe, Lawrence E. Larson, CDMA Mobile Radio Design, Artech House Boston 1 London, www.artechhouse.com, 2000.

[2] Olivier Bouchet et. al, Free-Space Opticss, London W1T 5DX Newport Beach, CA 92663 UK, www.iste.co.uk, 2004. 
[3] Dong-Yiel Song et. al, $4 \times 10 \mathrm{~Gb} / \mathrm{s}$ terrestrial optical free space transmission over $1.2 \mathrm{~km}$ using an EDFA preamplifier with $100 \mathrm{GHz}$ channel spacing, Journal of Optics Express, Vol. 7, No. 82, 2000.

[4] Neda Cvijetic, Stephen G. Wilson, And Maïté Brandt-Pearce,Receiver Optimization In Turbulent Free-Space Optical MIMO Channels With APD and Q-Ary PPM, IEEE Photonics Technology Letters, Vol 19, NO. 2, January 15, 2007

[5] X. Zhu and J. M. Kahn, Free-space optical communication through atmospheric turbulence channels, IEEE Transactions on Communications, vol. 50, pp. 1293-1300, Aug. 2002.

[6] Theodoros A. Tsiftsis, Harilaos G. Sandalidis, George K. Karagiannidis, and Murat Uysal, Optical Wireless Links with Spatial Diversity over Strong Atmospheric Turbulence Channels, IEEE Transactions On Wireless Communications, Vol. 8, No. 2, February 2009

[7] Bikram Beri, Neel Kamal, WDM Based FSO Link Optimizing For 180km Using Bessel Filter, International Journal Of Research In Engineering And Technology, Volume: 03 Issue: 3 Maret 2014

[8] Larry C. Andrews and Ronald L. Philips, Laser Beam Propagation through Random Media, 2nd Ed., SPIE Press, Washington USA, 2005.

[9] Ruike Yang, Qi Liu, Zhensen Wu, Effects of Atmospheric Turbulence Scintillation on the Error Performance of Partially Coherent Laser Communication, Antennas and Propagation, 2009. EuCAP 2009. 3rd European Conference on March 2009

[10] B.E.A.Saleh,M.C.Teich,"Fundamental of Photonics" 1991 